structed on an advanced, entirely new technological platform, much of which comes from our new publishing partner, Atypon. Our new Web site is just one part of the revolution in information technology and delivery. Electronic delivery modes continue to proliferate. Social networks, intranets, mobile applications, tablet computers and e-readers, and text messaging are changing the patterns of communication and delivery of information for physicians, scientists, students, and patients. Our aim is to continue to develop new options for electronic information delivery that will be of interest, use, and value to all.

Disclosure forms provided by the authors are available with the full text of this article at NEJM.org.

This article (10.1056/NEJMe1007409) was published on July 24, 2010, at NEJM.org.

1. Campion EW. The Journal's new presence on the Internet. N Engl J Med 1996;334:1129.

2. Campion EW, Anderson KR, Drazen JM. A new Web site and a new policy. N Engl J Med 2001;344:1710-1.

Copyright (c) 2010 Massachusetts Medical Society

\title{
The Initiation of Renal-Replacement Therapy — Just-in-Time Delivery
}

\author{
Norbert Lameire, M.D., Ph.D., and Wim Van Biesen, M.D., Ph.D.
}

Renal-replacement therapy for patients with endstage renal disease was introduced approximately 50 years ago, yet the optimal timing for the initiation of dialysis is still debated. In recent years there has been a trend toward initiating dialysis at a relatively high estimated glomerular filtration rate (GFR), ${ }^{1,2}$ based on the assumption that starting dialysis early may avert the many medical and social problems associated with advanced uremia. For example, in 1996, only 19\% of patients in the United States began dialysis therapy when the estimated GFR was higher than $10 \mathrm{ml}$ per minute per $1.73 \mathrm{~m}^{2}$ of body-surface area (early initiation), but by $2005,45 \%$ initiated dialysis early. ${ }^{3}$ Care for patients with end-stage renal disease requires massive economic and human resources. If many people start dialysis early, the need for an increase in staff and resources for dialysis is inevitable. Furthermore, premature initiation of renal-replacement therapy has a major impact on the daily life of a patient, given the personal burden of dialysis. Thus, defining the optimal timing for the initiation of dialysis is extremely important.

Retrospective studies, with all their inherent weaknesses, did not show a survival benefit with early initiation of dialysis. On the contrary, patients who started dialysis with a relatively low creatinine clearance ("late start") tended to survive longer. ${ }^{4,5}$ At least two recent studies attributed this somewhat unexpected finding to the higher number of coexisting conditions among patients who start dialysis at a higher estimated GFR. ${ }^{6,7}$ In addition, calculation of the estimated GFR is based on the serum creatinine concentration. The calculation of estimated GFR, whether it is based on the commonly used Modification of Diet in
Renal Disease (MDRD) equation or the CockcroftGault equation - or some other estimating equation - may be quite inaccurate when kidney function is extremely reduced. Although a low serum creatinine concentration generally indicates a better GFR, a low creatinine concentration may also be caused by decreased muscle mass due to malnutrition or may be induced by overhydration. In addition, the discussion of timing for the initiation of dialysis is confounded by the distinction between the timing of referral to the nephrologist and the timing of initiation of dialysis. Obviously, only patients who are referred to a nephrologist in a timely manner have the opportunity to plan the timing for the initiation of dialysis, because planned initiation requires appropriate care before dialysis is needed. ${ }^{8}$

In this issue of the Journal, Cooper et al. ${ }^{9}$ report results from the Initiating Dialysis Early and Late (IDEAL) study, a multicenter, randomized, controlled trial in which adult patients who have progressive end-stage renal disease and are already receiving care in nephrology units were assigned to planned initiation of hemodialysis or peritoneal dialysis when the estimated GFR was either 10 to $14 \mathrm{ml}$ per minute per $1.73 \mathrm{~m}^{2}$ (early start) or 5 to $7 \mathrm{ml}$ per minute per $1.73 \mathrm{~m}^{2}$ (late start). The patients in the two study groups were well matched with respect to baseline characteristics. After a median follow-up period of 3.59 years, patient survival and the frequency of adverse events were not significantly different between the two groups; however, there was a 6-month separation between the groups in the start time of dialysis.

The study design of the trial allowed the investigators to base the timing of the initiation of 
dialysis not only on the estimated GFR but also on the presence or new appearance of symptoms of uremia. In our view the appropriate use of this dual criterion is critical for the optimal interpretation of the results.

Do the results of the IDEAL trial imply that the initiation of dialysis can be delayed until an estimated GFR of 5 to $7 \mathrm{ml}$ per minute per $1.73 \mathrm{~m}^{2}$ is reached? Certainly not. In the late-start group, 322 patients $(76 \%)$ had to initiate dialysis when the estimated GFR was far above the 5 to $7 \mathrm{ml}$ per minute per $1.73 \mathrm{~m}^{2}$ range, owing to the development of symptoms of uremia, fluid overload, or various other reasons (as detailed in the Supplementary Appendix, available with the full text of the article at NEJM.org). As a result, the mean estimated GFR at the start of dialysis in the latestart group was $9.8 \mathrm{ml}$ per minute per $1.73 \mathrm{~m}^{2}$ — far above the target of 5 to $7 \mathrm{ml}$ per minute per $1.73 \mathrm{~m}^{2}$. We view this high number of necessary protocol violations as indicating that in actual practice, clinical symptoms and patient follow-up are of greater importance in decision making than the estimated GFR. In other words, the presence of symptoms of uremia led to the initiation of dialysis in the majority of the patients in the late-start group. One may question whether the significant difference in estimated GFR between the groups at the time of the initiation of dialysis (a mean difference of $2.2 \mathrm{ml}$ per minute per $1.73 \mathrm{~m}^{2}$ ) is clinically relevant, in view of the inaccuracy of estimated GFR in this low range. However, the important conclusion of the study is that waiting to initiate dialysis until signs of uremia appear does not jeopardize the patient and that starting renal-replacement therapy on the basis of a predefined estimated GFR value does not improve the outcome. Because the IDEAL study considered both estimated GFR and symptoms, the results of the study are difficult to compare with those of previous registry studies ${ }^{1,4,5}$ in which the decision to start dialysis early or late was based on estimated GFR alone and not on the presence of symptoms of uremia. Given the results of the study, the term "preemptive" initiation of dialysis may be used in the case of asymptomatic patients, as compared with "on-indication" initiation in the case of patients with symptoms or complications of uremia.

The main conclusion of this important study - that for asymptomatic patients renal-replacement therapy can be delayed by an average of 6 months - should be placed in perspective. An important prerequisite for a "wait and see" policy is careful clinical follow-up of each patient in order to avoid some of the life-threatening complications of uremia that may necessitate immediate renal-replacement therapy. All the patients in the trial had been followed for some time by their respective nephrologists and were well prepared to start dialysis. The study protocol explicitly advocated that the method of dialysis be selected, and a functioning peritoneal or vascular access be prepared, in advance, a policy that permits the immediate initiation of dialysis if the patient becomes symptomatic. Indeed, few patients in either group started dialysis with the use of a temporary access catheter. Conversely, the results of the study also imply that among asymptomatic patients, delaying the start of dialysis until a permanent access has been created does not jeopardize the outcome. Given the results of the study, the use of temporary catheters, with their high risks of infection and stenosis, can probably be avoided, and patients willing to start peritoneal dialysis can avoid temporary hemodialysis.

In our view, the IDEAL trial supports the currently recommended practice, in which most nephrologists start patients on renal-replacement therapy on the basis of clinical factors rather than numerical criteria such as the estimated GFR alone. ${ }^{10}$ Early referral to a nephrologist, a wellorganized patient-education program, and careful planning before dialysis is initiated are the cornerstones of such a strategy.

Disclosure forms provided by the authors are available with the full text of this article at NEJM.org.

From the University Hospital Ghent, University of Ghent, Ghent, Belgium.

This article (10.1056/NEJMe1006669) was published on June 27, 2010, at NEJM.org.

1. Cantero-Muñoz P, Ruano-Ravina A, Otero-González A, Sánchez-Guisande D, González Rodríguez L. Influence of early dialysis among patients with advanced chronic renal disease: results of a systematic review. Nephrol Dial Transplant 2010 May 5 (Epub ahead of print).

2. Rosansky SJ, Clark WF, Eggers P, Glassock RJ. Initiation of dialysis at higher GFRs: is the apparent rising tide of early dialysis harmful or helpful? Kidney Int 2009;76:257-61.

3. National Kidney Foundation. Excerpts from the United States Renal Data System 2007 annual data report. Am J Kidney Dis 2008;51:Suppl 1:S1-S304.

4. Stel VS, Dekker FW, Ansell D, et al. Residual renal function at the start of dialysis and clinical outcomes. Nephrol Dial Transplant 2009;24:3175-82.

5. Traynor JP, Simpson K, Geddes CC, Deighan CJ, Fox JG. Early initiation of dialysis fails to prolong survival in patients with end-stage renal failure. J Am Soc Nephrol 2002;13:2125-32.

6. Lassalle M, Labeeuw M, Frimat L, et al. Age and comorbidity may explain the paradoxical association of an early dialysis start with poor survival. Kidney Int 2010;77:700-7. 
7. Stel VS, Tomson C, Ansell D, et al. Level of renal function in patients starting dialysis: an ERA-EDTA Registry study. Nephrol Dial Transplant 2010 April 16 (Epub ahead of print).

8. Korevaar JC, van Manen JG, Boeschoten EW, Dekker FW, Krediet RT. When to start dialysis treatment: where do we stand? Perit Dial Int 2005;25:Suppl 3:S69-S72.
9. Cooper BA, Branley P, Bulfone L, et al. A randomized, controlled trial of early versus late initiation of dialysis. N Engl J Med 2010;363:609-19.

10. European best practice guidelines for peritoneal dialysis. Nephrol Dial Transplant 2005;20:Suppl 9:ix1-ix35.

Copyright (c) 2010 Massachusetts Medical Society.

\title{
Systemic Therapy for a Genetic Skin Disease
}

\author{
Leena Bruckner-Tuderman, M.D.
}

With an area of almost $2 \mathrm{~m}^{2}$, the human skin forms a large physical barrier between the organism and the environment. Diseases of the skin can have a severely negative effect on the quality and length of life of the persons affected.

Although effective treatments have been devised for common skin diseases, curative therapies do not exist for genetic skin disorders, of which there are nearly 400 . There are too few patients within each group to provide an incentive for the pharmaceutical industry to develop drugs. Scientists, however, have recognized the value of monogenic diseases as models for the investigation of therapeutic approaches. Preclinical testing of therapies involving genes, small interfering RNA (siRNA), proteins, and cells, ${ }^{1}$ both in animal models $^{2}$ and in pilot trials with individual patients, ${ }^{3-5}$ has fueled enthusiasm for evidence-based treatments of genetic skin diseases.

The systemic therapy for a genetic skin disease described by Wagner and colleagues in this issue of the Journal ${ }^{6}$ represents a leap forward. These investigators describe a phase 1-2 clinical trial of allogeneic bone marrow transplantation or umbilical-cord blood transplantation to treat epidermolysis bullosa.

Epidermolysis bullosa is a heterogeneous group of disorders characterized by chronic epithelial fragility $^{7}$; the key symptom in all forms is traumainduced skin blistering. It is caused by the mutation of 1 of at least 14 genes encoding proteins of the dermal-epidermal junction - a specialized basement-membrane zone that attaches the epidermis to the dermis. ${ }^{1,7}$ Patients have large, painful skin lesions, physical impairment, and a permanent need for assistance. For a patient with generalized epidermolysis bullosa, the estimated cost of symptomatic treatment of the skin alone exceeds $\$ 30,000$ each year.

One of the most severe of the epidermolysis bullosa subtypes is generalized recessive dys- trophic epidermolysis bullosa, ${ }^{8}$ which is caused by mutations in the gene encoding collagen VII (C7) and is characterized by a lack of this collagen and its polymers - the anchoring fibrils in the skin and mucosa. In recessive dystrophic epidermolysis bullosa, trauma-induced blistering and chronic, nonhealing wounds are associated with scarring. Joint contractures, mutilating deformities of the hands and feet, malnutrition, and growth retardation are secondary symptoms requiring continuous multidisciplinary management. A feared complication of this disorder is the development of squamous-cell carcinomas early in life. These cancers are aggressive, with a high propensity for metastasis.

Wagner and colleagues initiated their study after obtaining positive results on preclinical tests. ${ }^{9}$ Seven children with recessive dystrophic epidermolysis bullosa (between 15 months and 14.5 years of age) were treated with immunomyeloablative chemotherapy and subsequent bone marrow transplantation, umbilical-cord blood transplantation, or both. Before treatment, all the children had extensive blistering, with varying degrees of involvement of other organs. Five of the seven graft recipients were alive between 130 and 799 days after transplantation and had a substantial proportion of donor cells in the skin (median, $20 \%$ ). In five of the six children who could be evaluated, the authors observed an increase of $\mathrm{C7}$ at the dermal-epidermal junction. They did not, however, observe distinct anchoring fibrils. The children's parents reported improved wound healing and less blistering within the first 100 days. Presumably, the healthy hematopoietic donor cells in the skin synthesized and secreted C7, which was then incorporated into the dermalepidermal junction.

These data are consistent with studies in mice indicating that 30 to $40 \%$ of physiologic C7 levels is sufficient for clinically significant skin 